\title{
Retropharyngeal Calcific Tendinitis
}

ROBERT M. SIWIEC, MD; DAVID J. KUSHNER, DO; JEANETTE L. MORRISON, MD, Advocate Lutheran General Hospital, Internal Medicine, 1775 Dempster Street, Park Ridge, Illinois 60068, USA. Address reprint requests to Dr. Siwiec. E-mail: Robert.Siwiec-MD@advocatehealth.com. J Rheumatol 2009;36:1546-7; doi:10.3899/jrheum.081161

We describe a case of retropharyngeal calcific tendinitis, an uncommon benign condition that was first described by Hartley in $1964^{1}$.

A 37-year-old woman presented with a 3-day history of right occipital neck pain and odynophagia. There was no associated fever or recent illness. She denied any trauma or history of injury to the neck area. Ear-nose-throat and neck examinations were normal apart from limited neck motion with right occipital tenderness but no lymphadenopathy. Laboratory studies including white blood cell count, erythrocyte sedimentation rate, and $\mathrm{C}$-reactive protein were normal. Magnetic resonance imaging of the cervical spine was performed. T2-weighted image showed an area of high signal intensity extending from $\mathrm{C} 1$ to $\mathrm{C} 5$ consistent with prevertebral edema (Figure 1, arrow), and a hypointense area anterior to $\mathrm{C} 1-\mathrm{C} 2$ consistent with calcification (Figure 1 , arrowhead). A diagnosis of retropharyngeal calcific tendinitis was made, and the patient was treated with a nonsteroidal antiinflammatory medication. Her symptoms resolved completely in 6 days.

Retropharyngeal calcific tendinitis ${ }^{1}$ is an uncommon benign condition caused by an aseptic inflammatory process in the superior oblique tendon fibers of the longus colli muscle, triggered by deposition of calcium hydroxyapatite crys-

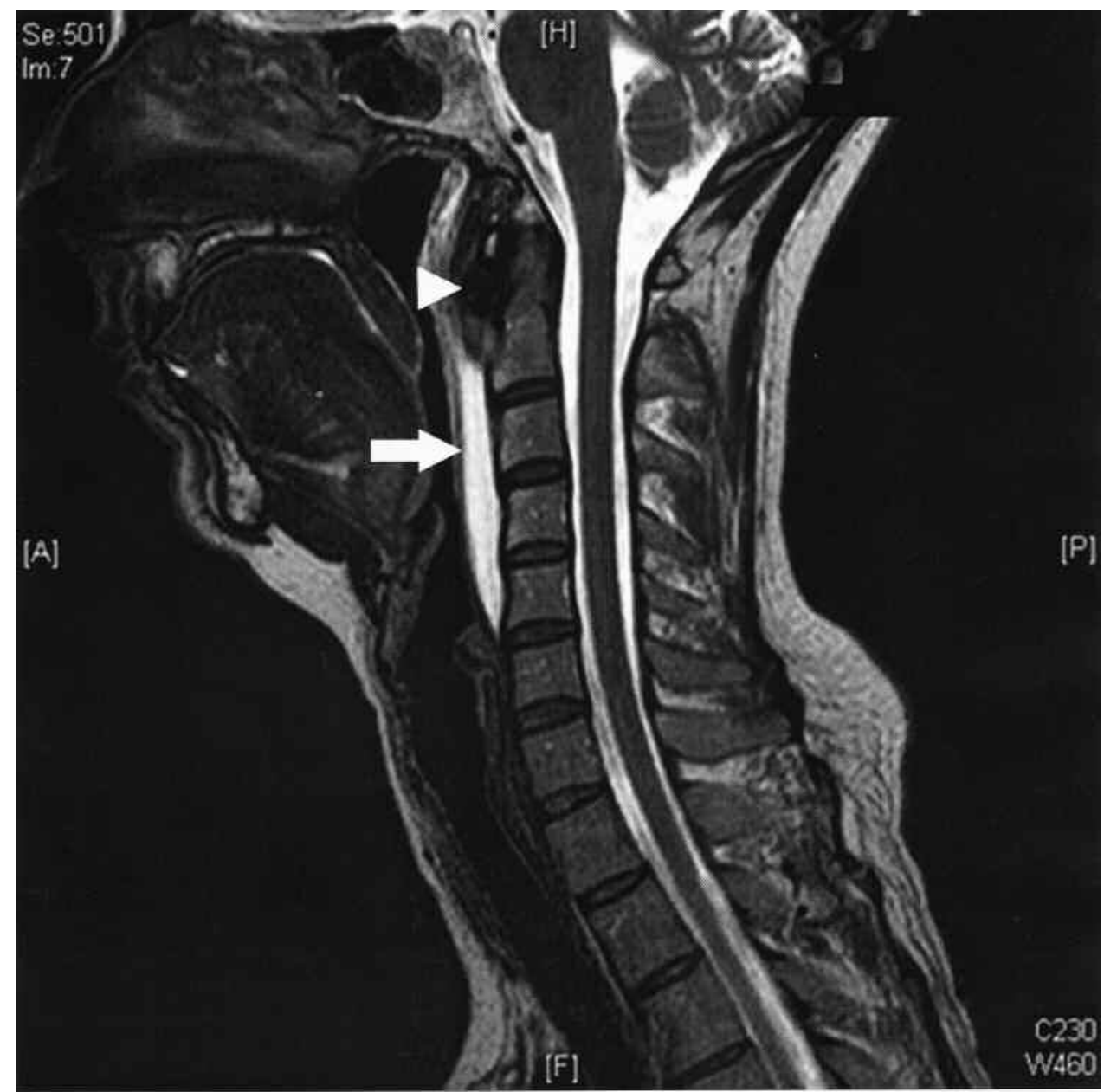

Figure 1. T2-weighted image showing an area of high signal intensity extending from $\mathrm{C} 1$ to $\mathrm{C} 5$ consistent with prevertebral edema (arrow) and a hypointense area anterior to $\mathrm{C} 1-\mathrm{C} 2$ consistent with calcification (arrowhead). 
tals ${ }^{2}$. The pathogenesis of crystal deposition in these fibers remains unclear, although repetitive trauma, ischemia, necrosis, and genetic predisposition have been suggested as possible etiologies ${ }^{3}$. The most common symptoms are neck pain, neck rigidity, dysphagia, odynophagia, and headache. Laboratory data are usually normal, but inflammatory changes may be observed with elevated erythrocyte sedimentation rate and mildly elevated white blood cells ${ }^{4}$. The pathognomonic radiographic findings consist of prevertebral soft tissue swelling typically extending from $\mathrm{C} 1$ to $\mathrm{C} 4$ and calcification anterior to $\mathrm{C} 1-\mathrm{C} 2$ at the insertion of the superior oblique tendon of the longus colli muscle ${ }^{1,2,4,5}$. Symptoms usually resolve over the course of 1 to 2 weeks treated conservatively with nonsteroidal antiinflammatory medications and avoidance of aggravating neck movements.

\section{REFERENCES}

1. Hartley J. Acute cervical pain associated with retropharyngeal calcium deposit: a case report. J Bone Joint Surg Am 1964;46:1753-4.

2. Ring D, Vaccaro AR, Scuder G, Pathria MN, Garfin SR. Acute calcific retropharyngeal tendinitis: clinical presentation and pathological characterization. J Bone Joint Surg Am 1994;76:1636-42.

3. DeMaeseneer M, Vreugde S, Laureys S, Sartoris DJ, DeRidder F, Osteaux M. Calcific tendinitis of the longus colli muscle. Head Neck 1997;19:545-8

4. Haun CL. Retropharyngeal tendinitis. AJR Am J Roentgenol 1978;130:1137-40.

5. Artenian DJ, Lipman JK, Scidmore GK, Brant-Zawadzki M. Acute neck pain due to tendinitis of the longus colli: CT and MRI findings. Neuroradiology 1989;31:166-9. 